\title{
Brucellosis:
}

\section{Haemorrhagic Pleural Effusion}

\author{
A Case Report
}

\author{
Awadh R. Al-Anazi Shahid Aziz Mona A. Fouda \\ Department of Medicine, College of Medicine, King Khalid University Hospital, Riyadh, Saudi Arabia
}

\section{Key Words}

Brucellosis · Haemorrhagic pleural effusion · Lung decortication

\begin{abstract}
Objectives: To describe haemorrhagic pleural effusion as a rare complication of brucellosis that finally needed lung decortication. Clinical Presentation and Intervention: A 37-year-old female presented with a 1-week history of fever, dry cough and pleuritic chest pain. Physical examination showed signs of right pleural effusion and hepatosplenomegaly. Complete blood count showed pancytopenia, white blood cells $2.9 / \mathrm{mm}^{3}$, haemoglobin $10 \mathrm{~g} / \mathrm{dl}$, platelets $131 / \mathrm{mm}^{3}$. Chest X-ray confirmed a moderate right pleural effusion, that was found to be exudative biochemically. Culture of pleural fluid and blood grew Brucella species. Fever subsided with Brucella chemotherapy, but pleural effusion persisted. Computed tomographic (CT) chest scan showed a large loculated pleural effusion, which failed to resolve despite repeated aspirations under CT guidance. Fluid was always found to be haemorrhagic. Finally, lung decortication was done with successful outcome. Conclusion: This case showed that brucellosis can cause haemorrhagic pleural effusion that needs lung decortication.
\end{abstract}

Copyright $\subset 2005$ S. Karger AG, Basel

\section{Introduction}

Brucellosis is a worldwide zoonotic disease [1] caused by the genus Brucella. It is estimated that the actual incidence of the disease is much higher than reported, because in many instances, the disease is not recognized or reported [2]. Consumption of raw milk and milk products and contact with animals remain the major sources of infection [3]. Humans are infected mainly by ingestion of raw milk and milk products, inhalation of infected particles, direct contact through abraded skin or mucous membranes with infected meat, liver or bone marrow and exposure to placenta of infected animals [2]. The organism has been isolated from breast milk and nursing mothers may infect their infants through breast-feeding [4]. The organism has also been isolated from human semen and there are case reports of sexual transmission [4]. Recent reports on the isolation of Brucella maris from marine animals can widen the epidemiological aspects of the disease [1]. Any organ system can be infected including bones, joints, heart, lung and central nervous system. A presumptive diagnosis of brucellosis is made by a positive serology test, which is then confirmed by isolation of the organism from blood and/or tissue cultures. We report a case of brucellosis complicated with haemorrhagic pleural effusion.

\begin{tabular}{|c|c|}
\hline KARGER & $\begin{array}{l}\text { (c) } 2005 \text { S. Karger AG, Basel } \\
1011-7571 / 05 / 0142-0118 \$ 22.00 / 0\end{array}$ \\
\hline $\begin{array}{l}\text { Fax +4161306 } 1234 \\
\text { E-Mail karger@karger.ch } \\
\text { www.karger.com }\end{array}$ & $\begin{array}{l}\text { Accessible online at: } \\
\text { www.karger.com } / \mathrm{mpp}\end{array}$ \\
\hline
\end{tabular}

Dr. Shahid Aziz

Department of Medicine (38), King Khalid University Hospital

PO Box 2925

Riyadh 11461 (Saudi Arabia)

E-Mail shahidaziz68@hotmail.com 


\section{Case Report}

A 37-year-old Saudi housewife presented with a 1-week history of fever, dry cough, right pleuritic chest pain and New York Heart Association class 2 exertional shortness of breath. She gave a history of raw milk ingestion and animal contact. Physical examination showed signs of right pleural effusion and hepatosplenomegaly. CBC showed pancytopenia with WBCs $2.1 / \mathrm{mm}^{3}, \mathrm{Hb} 10 \mathrm{~g} / \mathrm{dl}$, platelets $131 / \mathrm{mm}^{3}$ and ESR $62 \mathrm{~mm} / \mathrm{h}$. Chest X-ray confirmed a moderate right pleural effusion. A diagnostic pleural tap showed a haemorrhagic pleural fluid with $\mathrm{pH} \mathrm{7,} \mathrm{protein} 50 \mathrm{~g} / \mathrm{dl}$, glucose $3.5 \mathrm{mmol} / \mathrm{l}$, WBC $2,000 / \mathrm{mm}^{3}$ (polymorphs $80 \%$ and lymphocytes $20 \%$ ), RBCs $>100,000 / \mathrm{mm}^{3}$. Gram stain was negative and no acidfast bacilli (AFB) were seen with special stain. Pleural fluid and blood cultures grew Brucella species. Brucella agglutinin antibodies were positive for Brucella abortus with a titre of 1:5,120 which increased to 1:10,240 within 1 week. Bone marrow examination revealed a normocellular marrow, no granulomas and did not grow Brucellae or Mycobacterium tuberculosis in culture after incubating for 8 weeks at $37^{\circ} \mathrm{C}$ with $10 \% \mathrm{CO}_{2}$. Serum antinuclear antibodies were negative.

She was started on doxycycline $100 \mathrm{mg}$ per oral twice daily and cotrimoxazole $960 \mathrm{mg}$ per oral twice daily. Fever subsided after 5 days and she continued to take oral doxycycline and cotrimoxazole for 3 months, but pleural effusion and shortness of breath persisted. Computed tomographic (CT) scan of the chest showed a large loculated pleural effusion which failed to resolve despite repeated aspirations under CT guidance and later, chest intubation failed to clear the pleural cavity. Pleural fluid was found to be haemorrhagic. Finally, lung decortication was done, which made the pleural fluid and shortness of breath disappear. Histopathological examination of the pleural tissue showed non-specific chronic inflammatory cell infiltrate, and was negative for granulomas, malignant cells, or acidfast bacilli. Tissue culture did not grow any organism including Mycobacterium tuberculosis after incubation at $37^{\circ} \mathrm{C}$ with $10 \% \mathrm{CO}_{2}$ for 8 weeks.

She was followed up in the outpatient clinic for 6 months. There was no pleural collection and the hepatosplenomegaly had regressed. Haematological indices were found to be normal.

\section{Discussion}

Brucellosis is hyperendemic in Saudi Arabia [4] with more than 8,000 cases reported each year to public health authorities [8]. During 1998, brucellosis was the most reported communicable disease (22.5\%) in Saudi Arabian national guard community $[4,5]$. The reported incidence varied from $1.1 \%$ in administrative personnel to $8.9 \%$ in butchers.

Respiratory complications in brucellosis are mostly mild and take the form of a 'flu-like' illness with sore throat, tonsillitis and mild dry cough [6]. More serious manifestations are rare [7-9] and may cause pleurisy, pneumonia, lung abscess and hilar lymphadenopathy [8]. Pleural effusion and empyema are even rarer.
The reports of pleural effusion in brucellosis are limited to only a few case reports $[3,8-10]$. The characteristics of pleural fluid in brucellosis are of an exudative effusion with high proteins, low glucose, low $\mathrm{pH}$ and predominant lymphocytic cells $[3,9,10]$ greatly resembling pleural effusion of tuberculous. In one case report of a patient with brucellosis, the pleural fluid had a high adenosine deaminase level as seen in tuberculous pleural effusion [10]. In areas where both brucellosis and tuberculosis are endemic, differentiation between the two can be difficult. However, Brucella serum agglutinins and positive pleural fluid culture can help to differentiate brucellosis from tuberculous pleural effusion.

Our patient was unique and differed from previous case reports $[9,10]$ because pleural fluid cytology showed $80 \%$ polymorphonuclear cells and only $20 \%$ lymphocytes. Absence of polymorphonuclear cells in pleural fluid is associated with favourable outcome to conservative treatment [3]. Our patient with predominant polymorphonuclear cells in the pleural fluid did not respond well to conservative treatment with oral doxycycline and cotrimoxazole. The recommended treatment $[6,11]$ includes a combination of oral doxycycline $100 \mathrm{mg}$ twice daily with an aminoglycoside like streptomycin $1 \mathrm{~g}$ intramuscularly daily, of which streptomycin is given for only 4 weeks while doxycycline is continued for an additional 2-3 months. After discontinuation of streptomycin, oral rifampicin $600 \mathrm{mg}$ once daily is added with doxycycline to complete the rest of the treatment. In children and pregnant women, a combination of cotrimoxazole and rifampicin is used for 2-3 months [6, 11]. Patients with neurobrucellosis and Brucella endocarditis may need prolonged treatment with three or more drugs including rifampicin. Patients with Brucella meningitis may need treatment for 6-9 months [12].

We suggest that in patients with Brucella pleural effusion, the presence of predominant polymorphonuclear cells should alert the treating clinician that conservative treatment may not be adequate alone and patients may need surgical intervention. Further, we suggest that brucellosis should be considered as one of the causes of haemorrhagic pleural effusion of unknown cause, particularly in areas where brucellosis is endemic, like Saudi Arabia.

\section{Conclusion}

This case showed that brucellosis can cause haemorrhagic pleural effusion that needed lung decortication. 


\section{References}

1 Corbel MJ: Brucellosis: An overview. 1st Int Conf on Emerging Zoonoses. Emerg Infect Dis 1997;3:213-221.

2 Monir Madkour M: Brucellosis in Man and Animals. London, Butterworth-Heinemann, 1989.

3 Kerem E, Diav A, Navon P, Branski D: Pleural fluid characteristics in pulmonary brucellosis. Thorax 1995;49:89-90.

4 Dajani Y, Masoud A, Barakat H: Epidemiology and diagnosis of human brucellosis in Jordan. J Trop Med Hyg 1989;92:209-214.

$\checkmark 5$ Memish Z: Brucellosis in Saudi Arabia: Prospects and challenges. J Chemother 2001;13: $11-17$.
6 Fauci AS, Braunwald E, Isselbacher KJ, Wilson JD, Martin JB, Kasper DL, Hauser SL, Longo DL (eds): Harrison's Principles of Internal Medicine. London, McGraw Hill, 1998, pp 969-971.

7 Kochar DK, Sharma BV, Gupta S, Jain R, Gavri LA, Srivastava T: Pulmonary manifestations in brucellosis: A report on seven cases from Bikaner (Northwest India). J Assoc Physicians India 2003;51:33-36.

8 Lubani MM, Lulu AR, Araj GF, Khateeb MI, Qurtom MA, Dudin KI: Pulmonary brucellosis. Q J Med 1989;71:319-324.
-9 Papris SA, Maniati MA, Haritou A, Constantopoulous SH: Brucella haemorrhagic pleural effusion. Eur Respir J 1994; 7:1369-1370.

10 Dikensoy O, Namiduru M, Hocaoglu S, Ikidag B, Filiz A: Increased pleural fluid adenosine deaminase in brucellosis is difficult to differentiate from tuberculosis. Respiration 2002;69: 556-559.

11 Ledingham JGG, Warrell DA: Concise Oxford Textbook of Medicine. Oxford, New York, Oxford University Press, 2000, pp 1634-1636.

12 Armstrong D, Cohen J: Infectious diseases; in Slack MPE (ed): Brucellosis. St Louis, Mosby, 1999, vol 8, pp 3-5. 